\title{
Prevalence and risk factors of hypotension associated with preload-dependence during intermittent hemodialysis in critically ill patients
}

Laurent Bitker ${ }^{1}$, Frédérique Bayle ${ }^{1}$, Hodane Yonis ${ }^{1,2}$, Florent Gobert ${ }^{1,2}$, Véronique Leray ${ }^{1}$, Romain Taponnier ${ }^{1}$, Sophie Debord ${ }^{1,2}$, Alina Stoian-Cividjian ${ }^{1,2}$, Claude Guérin ${ }^{1,2,3}$ and Jean-Christophe Richard ${ }^{1,2,4^{*}}$

\begin{abstract}
Background: Hypotension is a frequent complication of intermittent hemodialysis (IHD) performed in intensive care units (ICUs). Passive leg raising (PLR) combined with continuous measurement of cardiac output is highly reliable to identify preload dependence, and may provide new insights into the mechanisms involved in IHD-related hypotension. The aim of this study was to assess prevalence and risk factors of preload dependence-related hypotension during IHD in the ICU.

Methods: A single-center prospective observational study performed on ICU patients undergoing IHD for acute kidney injury and monitored with a PiCCO ${ }^{\circledR}$ device. Primary end points were the prevalence of hypotension (defined as a mean arterial pressure below $65 \mathrm{~mm} \mathrm{Hg}$ ) and hypotension associated with preload dependence. Preload dependence was assessed by the passive leg raising test, and considered present if the systolic ejection volume increased by at least $10 \%$ during the test, as assessed continuously by the $\mathrm{PiCCO}^{\circledR}$ device.

Results: Forty-seven patients totaling $107 \mathrm{IHD}$ sessions were included. Hypotension was observed in $61 \mathrm{IHD}$ sessions ( $57 \%, \mathrm{Cl}_{95 \%}$ : 47-66 \%) and was independently associated with inotrope administration, higher SOFA score, lower time lag between ICU admission and IHD session, and lower MAP at IHD session onset. Hypotension associated with preload

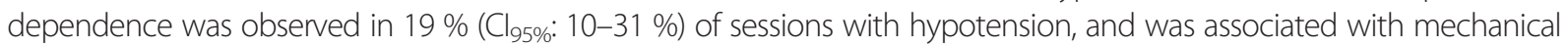
ventilation, lower SAPS II, higher pulmonary vascular permeability index (PVPI) and dialysate sodium concentration at IHD session onset. ROC curve analysis identified PVPI and mechanical ventilation as the only variables with significant diagnostic performance to predict hypotension associated with preload dependence (respective AUC: 0.68 (Cl $95 \%$ : $0.53-$ 0.83 ) and 0.69 ( $\mathrm{Cl}_{95 \%}$ : 0.54-0.85). A PVPI $\geq 1.6$ at IHD session onset predicted occurrence of hypotension associated with

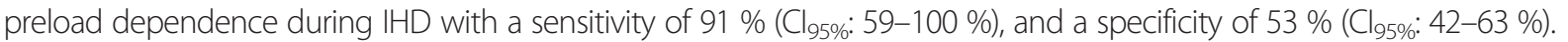

Conclusions: The majority of hypotensive episodes occurring during intermittent hemodialysis are unrelated to preload dependence and should not necessarily lead to reduction of fluid removal by hemodialysis. However, high PVPI at IHD session onset and mechanical ventilation are risk factors of preload dependence-related hypotension, and should prompt reduction of planned fluid removal during the session, and/or an increase in session duration.
\end{abstract}

Keywords: Acute kidney injury, Renal replacement therapy, Hemodynamics, Cardiac output, Circulatory failure, Cardiovascular monitoring

\footnotetext{
* Correspondence: j-christophe.richard@chu-lyon.fr

${ }^{1}$ Service de Réanimation Médicale, Hôpital De La Croix Rousse, Hospices

Civils de Lyon, 103 Grande Rue de la Croix Rousse, 69004 Lyon, France

${ }^{2}$ Faculté de médecine Lyon-Est, Université de Lyon, Université Lyon I, 92 Rue

Pasteur, 69007 Lyon, France

Full list of author information is available at the end of the article
}

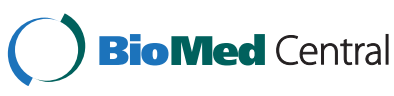

C 2016 Bitker et al. Open Access This article is distributed under the terms of the Creative Commons Attribution 4.0 International License (http://creativecommons.org/licenses/by/4.0/), which permits unrestricted use, distribution, and reproduction in any medium, provided you give appropriate credit to the original author(s) and the source, provide a link to the Creative Commons license, and indicate if changes were made. The Creative Commons Public Domain Dedication waiver (http://creativecommons.org/publicdomain/zero/1.0/) applies to the data made available in this article, unless otherwise stated. 


\section{Background}

Hypotension is a major complication of intermittent hemodialysis (IHD) in intensive care units (ICUs), and may impair efficiency of renal replacement therapy, increase mortality, and decrease renal recovery after acute kidney injury [1]. Although continuous renal replacement therapy techniques are now recommended for hemodynamically unstable patients, these may be replaced by IHD once hemodynamic stability has been achieved [1]. Even though dedicated ICU practice guidelines aiming to improve hemodynamic tolerance of IHD [2] are applied, hypotension rates ranging from $17 \%$ to $56 \%$ are still reported [2-6]. The common consequence of IHD-related hypotension is to discontinue the fluid removal for the rest of the IHD session, with the main consequence of impairing fluid balance control, which has been repeatedly shown as a major determinant of mortality in patients with septic shock or acute respiratory distress syndrome [7-9].

However, this management relies on the assumption that the underlying cause of hypotension is hypovolemia. Yet, several other determinants of hypotension during hemodialysis have been identified such as reduced cardiac output of various origins (hypocalcemia, diastolic dysfunction,...) or alterations of the vasomotor tone related to positive thermal balance, membrane/circuit bio-incompatibility or ionic imbalance, among others [10-13].

Previous studies have used the Swan-Ganz catheter to investigate hemodynamic effects of IHD [10, 12], but this technique is not reliable to predict preload dependence (cardiac output increase in response to fluid administration) during acute circulatory failure [14]. Several modern cardiac output monitoring devices with fast response time have now the potential to reliably classify hypotensive episodes as dependent or non-dependent on cardiac preload [15]. Passive leg raising (PLR) combined with continuous measurement of cardiac output is a highly reliable bedside method to identify preload dependence in a large variety of clinical settings in the ICU (spontaneous breathing and deeply sedated patients, regular or irregular cardiac rhythm) [16]. We hypothesize that this technique, by reliably classifying hypotension as related or unrelated to cardiac preload, would help the management of fluid removal during IHD. However, to date, no study has attempted to evaluate the prevalence of preload dependence-related hypotension during IHD in ICU patients.

The aim of this study was to assess the prevalence of hypotension and preload dependence-related hypotension episodes in critically ill patients undergoing IHD. Secondary objectives were (1) to identify risk factors for hypotension and hypotension related to preload dependence during IHD in ICU and (2) to assess diagnostic performance of variables associated with hypotension related to preload dependence.

\section{Methods}

Study design

This is a prospective observational single-center study performed between May 1, 2012 and May 31, 2014 in a 15-bed medical ICU. The study was approved by an ethics committee (CECIC Rhône-Alpes-Auvergne, Grenoble, France, IRB 5921), which waived the requirement for informed consent given the observational nature of the study.

\section{Patients}

To be eligible the subjects had to fulfill all the following inclusion criteria: age of 18 years or older, staying in our ICU, $\mathrm{PiCCO}^{\circ}$ device (Pulsion Medical Systems, Feldkirchen, Germany) already in place for acute circulatory failure, and acute kidney injury requiring renal replacement therapy with IHD [1]. Exclusion criteria were pregnancy, lower limb amputation, excessive nurse's workload, known obstruction of inferior vena cava, and former inclusion in the study during a previous ICU admission. Multiple IHD sessions per patient during the same ICU stay were possibly eligible, should inclusion and exclusion criteria be fulfilled at IHD session onset.

\section{IHD sessions}

In our ICU the IHD sessions are managed by a specific team of technical nurses, the indication and settings of IHD sessions being the responsibility of the clinician in charge of the patient, in accordance with current practice guidelines [1] (continuous renal replacement therapy being used as a first-line technique in hemodynamically instable patients). IHD was performed with either INNOVA (Gambro Hospal, Meyzieu, France) or AK200 Ultra S (Gambro AB, Lund, Sweden) hemodialysis generators, Nephral ST 300 AN69ST dialysate membranes (Gambro Hospal, Meyzieu, France), and dialysate concentrate solutions with $1.75 \mathrm{mmol} / \mathrm{L}$ calcium concentration. IHD settings regarding blood and dialysate flow rate, dialysate temperature and dialysate sodium concentration were prescribed by the physician in charge, according to published practice guidelines [2].

\section{Hemodynamic management}

Arterial and central venous blood pressures were continuously monitored, by using arterial femoral and jugular vein catheters, respectively, connected to Intellivue MP40 monitor equipped with the $\mathrm{PiCCO}^{\circ}$ technology module (Philips Healthcare, Andover, MA, USA). Cardiac output was assessed using the $\mathrm{PiCCO}^{\circ}$ device, calibrated with the transpulmonary thermodilution technique, using a triplicate intravenous infusion of $15 \mathrm{~mL}$ cold serum saline, immediately before the IHD session. Cardiac output was then continuously monitored using pulse contour analysis with the $\mathrm{PiCCO}^{\circ}$ device during the sessions, using the pre-IHD thermodilution cardiac output value for calibration. 
Mean arterial pressure (MAP) was targeted between 65 and $75 \mathrm{~mm} \mathrm{Hg}$ in patients under vasopressor therapy. Hypotension was defined as the first occurrence of MAP below $65 \mathrm{~mm} \mathrm{Hg}$ during the session. Once hypotension occurred, a PLR test was performed from the supine position by lifting the lower limbs at $45^{\circ}$ for 1 minute. The test was also performed before the initiation of the IHD session. Preload dependence was deemed present if stroke volume increased by at least $10 \%$ during the PLR. The physician response to preload-dependent hypotension, regarding fluid administration, reassessment of water balance or IHD session duration, was not protocolized.

\section{Data collection}

The following variables were recorded at inclusion: demographic and anthropometric data, time of ICU admission, admission category, Simplified Acute Physiology Score (SAPS) II [17] and reason for $\mathrm{PiCCO}^{\circ}$ monitoring.

The following variables were recorded at IHD session onset: Sequential Organ Failure Assessment (SOFA) score [18], heart rate, MAP, central venous pressure (CVP), cardiac index, extravascular lung water index, pulmonary vascular permeability index (PVPI), vasopressor administration and dose, inotrope administration, arterial lactate, need for mechanical ventilation and IHD settings.

\section{End points}

Primary end points were the prevalence of hypotension and hypotension associated with preload dependence as assessed by passive leg raising, respectively.

Secondary end points were the identification of risk factors for both hypotension and hypotension related to preload dependence, and the diagnostic performance of variables associated with hypotension related to preload dependence during IHD.

\section{Statistical analysis}

Statistical analyses were performed using R software [19]. A $p$ value below 0.05 was chosen for statistical significance. The statistical unit was the IHD session. Power of the study was computed using the normal approximation confidence interval method [20]. We calculated that with a sample size of at least 96 IHD sessions, the study would provide at worst a $\pm 10 \%$ precision in the $95 \%$ confidence interval of the prevalence of hypotension and hypotension related to preload dependence during IHD. Medians and interquartile ranges were reported for continuous variables, and counts in each category with corresponding percentages are given for categorical variables. Ninety-five percent confidence intervals $\left(\mathrm{CI}_{95 \%}\right)$ for proportions were calculated using the Wilson score test.

Since some patients were studied during several IHD sessions, quantitative variables were compared between groups of sessions (with hypotension vs. without hypotension, and with hypotension and preload dependence vs. with hypotension without preload dependence) with a linear mixed model, using group as variable with a fixed effect, and patient as variable with a random effect [21]. Qualitative variables were compared similarly with a mixed logistic regression model, using patient as variable with a random effect.

Quantitative and qualitative variables associated with hypotension with a $p$ value below 0.1 in univariate analysis (using a mixed logistic regression model with patient as variable with a random effect) were selected for inclusion in a multivariable mixed logistic regression model, using backward stepwise descending selection [22]. Low prevalence of hypotension with preload dependence precluded the use of a multivariate logistic regression model.

Diagnostic performance of variables associated with preload-dependent hypotension was tested by computation of the area under the curve (AUC) of the receiver operating characteristic (ROC) curve [23]. The optimal cutoff values were computed using the Youden J statistic method [24].

\section{Results \\ Population}

During the study inclusion period, 1462 patients were admitted to the ICU, and 47 (median age 69 [63-78] years) were included in the study (see Additional file 1). Median SAPS II score was 53 [39-61], 32 patients were male (68\%), and 45 patients (96\%) were admitted with a medical admission category. Justification for $\mathrm{PiCCO}^{\circ}$ monitoring was septic shock in 26 patients (55\%), cardiogenic shock in 10 patients $(21 \%)$, hemorrhagic shock in 4 patients (9\%), non-septic vasoplegic shock in 4 patients $(9 \%)$ and other shocks in 3 patients (6\%). Patients' characteristics at the onset of IHD session are reported in Table 1.

\section{IHD sessions}

One hundred and seven IHD sessions were studied. Median number of IHD sessions per patient was three [2-5]. Twenty-seven patients underwent two or more IHD sessions. Details regarding IHD sessions are reported in Table 2. Missing values for each variable are reported in Additional file 2. Compliance to practice guidelines [2] to prevent hemodynamic instability during IHD sessions was high (see Additional file 3).

\section{Hypotension}

Hypotension was observed during 61 (57 \%, $\mathrm{CI}_{95 \%}$ : 47$66 \%)$ IHD sessions (Fig. 1), with a median time from IHD session onset of 35 [15-95] minutes. Effective fluid removal at hypotension onset was 300 [30-950] $\mathrm{mL}$. Comparisons between IHD sessions with hypotension and without hypotension are presented in Table 3. 
Table 1 Patients' characteristics at hemodialysis session onset

\begin{tabular}{|c|c|}
\hline Characteristics & Overall population \\
\hline Mechanical ventilation & $39(36 \%)$ \\
\hline SOFA score & $8[7-11]$ \\
\hline Vasopressor administration & $53(50 \%)$ \\
\hline Vasopressor dose $\left(\mu \mathrm{g} \cdot \mathrm{kg}^{-1} \cdot \mathrm{min}^{-1}\right)$ & $0.00[0.00-0.15]$ \\
\hline Inotropes administration & $9(8 \%)$ \\
\hline Arterial lactate $\left(\mathrm{mmol} . \mathrm{L}^{-1}\right)$ & $1.4[1.1-1.8]$ \\
\hline $\begin{array}{l}\text { Elevated lactates above upper laboratory } \\
\text { limit }\left(2.2 \mathrm{mmol} \mathrm{L}^{-1}\right)\end{array}$ & $14(13 \%)$ \\
\hline Heart rate $\left(\mathrm{min}^{-1}\right)$ & 90 [80-98] \\
\hline Mean arterial pressure $(\mathrm{mm} \mathrm{Hg})$ & $75[68-80]$ \\
\hline Mean arterial pressure below $65 \mathrm{~mm} \mathrm{Hg}$ & $8(7 \%)$ \\
\hline Central venous pressure $(\mathrm{mm} \mathrm{Hg})$ & $8[6-12]$ \\
\hline Cardiac index $\left(L \cdot \mathrm{min}^{-1} \cdot \mathrm{m}^{-2}\right)$ & $3.5[2.9-4.0]$ \\
\hline Indexed systemic vascular resistance (dyne.s. $\mathrm{cm}^{-5}$ ) & 1525 [1324-1864] \\
\hline Extravascular lung water (mL.kg ${ }^{-1}$ PBW) & $7.9[6.0-9.9]$ \\
\hline Extravascular lung water $>7 \mathrm{~mL} \cdot \mathrm{kg}^{-1} \mathrm{PBW}$ & $64(60 \%)$ \\
\hline Pulmonary vascular permeability index & $1.6[1.3-2.0]$ \\
\hline
\end{tabular}

Data are median [first quartile - third quartile] or number of sessions (percentage of the total number of sessions studied)

PBW predicted body weight, SOFA Sequential Organ Failure Assessment score

In sessions complicated by at least one hypotensive episode, SOFA score was significantly higher $(10$ [8-11] vs. 7 $[6-9], p=0.008)$, and mean arterial pressure at IHD session onset was significantly lower $(72 \mathrm{~mm} \mathrm{Hg}$ [67-79] vs. $78 \mathrm{~mm} \mathrm{Hg}$ [71-83], $p<0.01)$, as compared to sessions without hypotensive episode. The prevalence of preload dependence at IHD onset did not differ between hypotensive and non-hypotensive sessions (Table 3). Vasopressor dose, other hemodynamic parameters and IHD settings

Table 2 Characteristics of intermittent hemodialysis sessions

\begin{tabular}{ll}
\hline Characteristics & Overall population \\
\hline Number of IHD sessions & 107 \\
Number of IHD sessions per patient & $3[2-5]$ \\
$\begin{array}{l}\text { Time between ICU admission and first IHD } \\
\text { session (days) }\end{array}$ & $18[10-30]$ \\
Duration of IHD sessions (min) & $240[240-245]$ \\
Total fluid removal per session (mL) & $2620[1990-3240]$ \\
Fluid removal per hour (mL. $H^{-1}$ ) & $655[453-824]$ \\
$\begin{array}{l}\text { Dialyzer blood flow rate at IHD session onset } \\
\text { (mL.min }{ }^{-1} \text { ) }\end{array}$ & $250[250-272]$ \\
$\begin{array}{l}\text { Dialysate flow rate at IHD session onset }\left(\mathrm{mL} . \mathrm{min}^{-1}\right) \\
\text { Dialysate temperature at IHD session onset }\left({ }^{\circ} \mathrm{C}\right)\end{array}$ & $500[500-625]$ \\
$\begin{array}{l}\text { Dialysate sodium concentration at IHD session } \\
\text { onset (mmol. } \mathrm{L}^{-1} \text { ) }\end{array}$ & $145[144-150]$ \\
\hline
\end{tabular}

Data are medians [first quartile - third quartile] IHD intermittent hemodialysis were not statistically different between hypotensive and non-hypotensive sessions (Table 3).

We performed a multivariate analysis of variables associated with hypotension during IHD sessions, using the following variables (see Additional file 4): time between ICU admission and IHD session, SOFA score, inotrope administration at IHD session onset, MAP at IHD session onset, and sodium conductivity at IHD session onset. SOFA score, time between ICU admission and IHD session, MAP and inotrope administration at IHD session onset were significantly and independently associated with hypotension status during IHD sessions (Table 4).

\section{Hypotension with preload dependence}

Two sessions were not assessed for preload dependence during hypotension and were therefore excluded from subsequent analysis. Hypotension associated with preload dependence was observed in 11 IHD sessions (19 \%, $\mathrm{Cl}_{95 \%}$ : 10-31 \% of sessions with hypotension). Comparisons in patients' characteristics and IHD settings associated with preload- and non-preload-dependent hypotension are available in Table 5.

In the preload-dependent hypotensive group, SAPS II score was significantly lower, while heart rate, PVPI, dialysate sodium concentration at IHD session onset were significantly higher, and mechanical ventilation was significantly more frequent ( $73 \%$ vs. $27 \%, p=0.01$ ). Among these variables, ROC curve analysis identified PVPI at IHD onset and mechanical ventilation as the only variables with significant diagnostic performance, as assessed by their AUC significantly different from 0.5 (Table 6). A PVPI $\geq 1.6$ at IHD session onset predicted occurrence of hypotension associated with preload dependence during IHD with a sensitivity of $91 \%\left(\mathrm{CI}_{95 \%}\right.$ : $59-100 \%)$, and a specificity of $53 \%\left(\mathrm{CI}_{95 \%}\right.$ : $\left.42-63 \%\right)$.

Both groups also differed at hypotension onset regarding continuous cardiac index variation from IHD onset, with a significantly greater decrease in the preload-dependent group ( $-25 \%$ [ $-33 \%$ to $-5 \%$ ] vs. $-3 \%$ [ $-16 \%$ to $3 \%$, $p<0.02$, Fig. 2).

\section{Discussion}

This study is the first to assess the prevalence of preload dependence during IHD in the ICU. The main findings are that (1) the majority of first hypotension episodes occurring during IHD are not related to preload dependence and hence to fluid removal by IHD; (2) hypotension during IHD is unrelated to dialysis settings when ICU dedicated practice guidelines to prevent hemodynamic instability are applied, and is mainly related to preexistent cardiovascular and organ dysfunction; (3) high PVPI and mechanical ventilation are risk factors for preload dependence-related hypotension during IHD and 


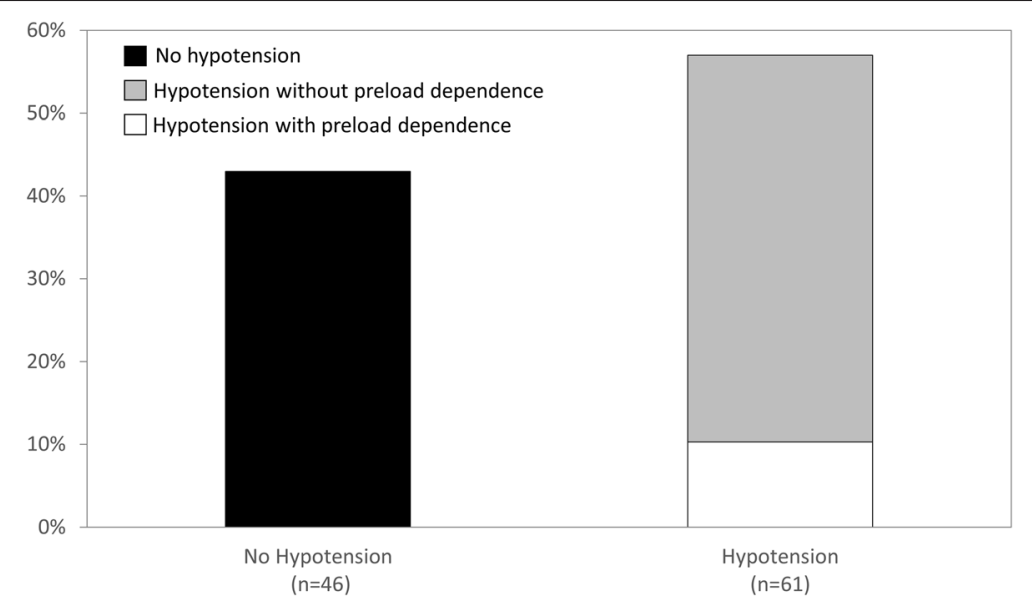

Fig. 1 Prevalence of hypotension during intermittent hemodialysis sessions

may prompt, if identified at IHD onset, reduction of planned fluid removal during the session, or increased session duration.

\section{Statistical methodology}

The use of IHD session as a statistical unit (and not patient) was purposely chosen, in accordance with the study aim (prevalence of hypotension during IHD sessions), and in line with previous studies addressing hypotension during IHD $[3,5,6]$. As a consequence, it was possible to obtain multiple measurements per patient, leading to the choice of mixed effects statistical modeling, which allows accurate analysis of unbalanced repeated measures data [25], since correlation between repeated observations is taken into account by the model.

\section{Hypotension during IHD sessions}

Hypotensive episodes were present in $57 \%$ of IHD sessions in the present study, a rate in the upper range of previous ICU studies, having documented hypotension rates ranging from 17 to $56 \%$ [2-6]. As compared to those studies, the present study is characterized by a higher prevalence of patients requiring vasopressors, similar SAPS II scores, and a lower percentage of patients requiring mechanical ventilation (see Additional file 5). While dissimilarities in case mix or dialysis settings between studies may explain this difference, heterogeneity between studies regarding the criteria defining hypotension may also be an alternative explanation (see Additional file 5), since there is no universally accepted standard to define hemodynamic instability during IHD in the ICU. However, despite differences in study settings, the present study identified similar independent risk factors for hypotension during IHD (e.g., lower arterial blood pressure at IHD onset and SOFA score [3]), confirming that patient-related factors of organ dysfunction are strongly associated with cardiovascular tolerance of IHD sessions. The association between time between ICU admission and IHD session and hypotension occurrence (higher time lag being identified as associated with less hypotension by an odds ratio significantly lower than 1) may be viewed as an incentive to favor continuous renal replacement therapy techniques at the initial phase of ICU stay, in line with current recommendations suggesting the use of this technique for hemodynamically unstable patients [1].

The protective role of cardiac inotrope regarding hypotension occurrence is unclear, and could be related to a specific subset of cardiac patients (although nonidentified in our population analysis), or a direct effect of this drug preventing low cardiac output. Conversely and in accordance with a recent study [3], we were unable to identify any association between hypotension occurrence during IHD and IHD settings. This may be a consequence of a strong adherence to IHD practice guidelines aiming to improve IHD hemodynamic tolerance [2] in both studies.

\section{Association between hypotension and preload dependence during IHD sessions}

The most striking result of this study is that a very limited proportion of hypotensive patients had a positive response to the PLR test and hence were deemed preload dependent (19\% of first hypotensive episodes), suggesting that the vast majority of first hypotensive episodes during IHD are not related to hypovolemia. We were unable to compare this finding with others, due to the lack of previously published studies on that matter. Our data suggests that the main cause of hypotension during IHD in our study is an alteration in the vasomotor tone, since median change from preIHD value in continuous cardiac index was close to 
Table 3 Comparisons between hemodialysis sessions with and without hypotension

\begin{tabular}{|c|c|c|}
\hline Characteristics & $\begin{array}{l}\text { No hypotension during session } \\
(n=46)\end{array}$ & $\begin{array}{l}\text { Hypotension during session } \\
(\mathrm{n}=61)\end{array}$ \\
\hline Age & 70 [64-79] & $67[58-78]$ \\
\hline Male gender & $38(83 \%)$ & $47(77 \%)$ \\
\hline SAPS ॥ & $53[40-62]$ & $53[37-60]$ \\
\hline \multicolumn{3}{|l|}{ Reasons for $\mathrm{PiCCO}^{\oplus}$ monitoring } \\
\hline - Septic shock & $30(65 \%)$ & $34(56 \%)$ \\
\hline - Cardiogenic shock & $7(15 \%)$ & $10(16 \%)$ \\
\hline - Other & $9(20 \%)$ & $17(28 \%)$ \\
\hline Time between ICU admission and IHD session (day) & 20 [12-34] & 16 [9-29] \\
\hline SOFA score at the day of IHD session & $7[6-9]$ & $10[8-11]^{\dagger}$ \\
\hline Mechanical ventilation at IHD session onset & $18(39 \%)$ & $21(34 \%)$ \\
\hline Inotrope at IHD session onset & $7(15 \%)$ & $2(3 \%)$ \\
\hline Vasopressor at IHD session onset & $20(43 \%)$ & $33(54 \%)$ \\
\hline Vasopressor dose at IHD session onset $\left(\mu \mathrm{g} \cdot \mathrm{kg}^{-1} \cdot \mathrm{min}^{-1}\right)$ & $0[0-0.10]$ & $0.04[0-0.19]$ \\
\hline Heart rate at IHD session onset $\left(\mathrm{min}^{-1}\right)$ & 89 [80-98] & 90 [81-98] \\
\hline MAP at IHD session onset (mm Hg) & 78 [71-83] & $72[67-79]^{\dagger}$ \\
\hline CVP at IHD session onset $(\mathrm{mm} \mathrm{Hg})$ & 9 [7-13] & $8[5-11]$ \\
\hline $\mathrm{Cl}$ at IHD session onset $\left(\mathrm{L} \cdot \mathrm{min}^{-1} \cdot \mathrm{m}^{-2}\right)$ & $3.7[3.0-3.9]$ & $3.4[2.8-4.0]$ \\
\hline ISVR at IHD session onset (dyne.s. $\mathrm{cm}^{-5}$ ) & $1561[1366-1907]$ & $1501[1262-1764]$ \\
\hline EVLWI at IHD session onset (mL.kg-1 PBW) & $8.2[6.1-10.9]$ & $7.7[6.0-9.7]$ \\
\hline PVPI at IHD session onset & $1.5[1.2-2.0]$ & $1.6[1.4-2.0]$ \\
\hline Preload dependence at IHD session onset & $1(2 \%)$ & $4(7 \%)$ \\
\hline Arterial lactates $\left(\mathrm{mmol} \mathrm{L}^{-1}\right)$ & $1.4[1.1-1.8]$ & $1.4[1.1-1.8]$ \\
\hline Elevated lactates above upper laboratory limit $\left(2.2{\left.\mathrm{mmol} . \mathrm{L}^{-1}\right)}^{-1}\right.$ & $4(9 \%)$ & $10(16 \%)$ \\
\hline Duration of IHD sessions (min) & $240[240-240]$ & $240[240-250]$ \\
\hline Total fluid removal during IHD session (mL) & 3000 [2162-3370] & 2400 [1670-3200] \\
\hline Fluid removal per hour during IHD session $\left(\mathrm{mL} . \mathrm{H}^{-1}\right)$ & $756[541-820]$ & 575 [400-829] \\
\hline Dialyzer blood flow rate at IHD session onset (L.min $\left.{ }^{-1}\right)$ & $250[250-270]$ & $250[250-275]$ \\
\hline Dialysate flow at IHD session onset $\left(\mathrm{mL} \cdot \mathrm{min}^{-1}\right)$ & $500[500-600]$ & $500[500-700]$ \\
\hline Dialysate temperature at IHD session onset $\left({ }^{\circ} \mathrm{C}\right)$ & $36[36-36]$ & $36[36-36]$ \\
\hline Dialysate sodium concentration at IHD session onset $\left(\mathrm{mmol}^{-\mathrm{L}^{-1}}\right.$ ) & $145[141-148]$ & $145[145-150]$ \\
\hline
\end{tabular}

Data are medians [first quartile - third quartile] or number (percentage)

$\mathrm{Cl}$ cardiac index, CVP central venous pressure, MAP mean arterial pressure, EVLWI extravascular lung water, IHD intermittent hemodialysis, ISVR indexed systemic vascular resistance, PBW predicted body weight, PVPI pulmonary vascular permeability index, SAPS II Simplified Acute Physiology Score II, SOFA Sequential Organ Failure Assessment score

${ }^{\dagger} p<0.05$ between groups

zero during hypotension in the non-preload-dependent hypotension group. Conversely and accordingly with the Franck-Starling mechanism, median change in continuous cardiac index between pre-IHD and hypotension significantly shifted toward more negative values in the preload-dependent group as compared to the nonpreload-dependent group (Fig. 2).

Among the five clinical variables associated with preload dependence-related hypotension, our analysis suggests that only PVPI at IHD onset and mechanical ventilation have useful diagnostic performance to identify at-risk patients at IHD onset, although the lack of multivariate analysis precludes any strong inference regarding these variables. High PVPI and a larger proportion of patients under mechanical ventilation may be related to increased risk of preload dependence hypotension by (1) respectively promoting increased plasma capillary leak in the pulmonary vasculature and (2) cardiopulmonary interaction by alteration of systemic venous return. Increased heart rate at IHD onset in the preload-dependent hypotension group 
Table 4 Risk factors associated with at least one hypotensive episode retained in the multivariable model

\begin{tabular}{|c|c|c|c|}
\hline Risk factor & Odds ratio & $\mathrm{Cl}_{95 \%}$ of odds ratio & $p$ value \\
\hline SOFA score, per one point increment & 1.34 & $1.13-1.76$ & $<0.01$ \\
\hline MAP at IHD session onset, per one $\mathrm{mm} \mathrm{Hg}$ increment & 0.93 & $0.84-0.98$ & 0.03 \\
\hline Inotrope at IHD session onset & & & 0.04 \\
\hline$\cdot \mathrm{No}^{+}$ & 1 & & \\
\hline - Yes & 0.13 & $0.00-0.76$ & \\
\hline Time between ICU admission and IHD session (day), per one point increment & 0.96 & $0.91-0.99$ & 0.04 \\
\hline
\end{tabular}

could be related to preexistent hypovolemia, although the lack of significant difference in the proportion of preload-dependent patients at IHD onset strongly argues against this hypothesis. The relationship between increased dialysate sodium concentration and preload dependence-related hypotension is unclear, as this should promote interstitium-to-plasma water transfer and increase IHD hemodynamic tolerance [2]. The association between lower SAPS II and occurrence of preload dependence-related hypotension is also unclear.

\section{Limitations}

Some limitations of the present study should be acknowledged. First, the single-center nature of this study could limit its generalizability, as patient case mix, selection of a subgroup of patients monitored by the $\mathrm{PiCCO}^{\circ}$ device, local practice of using IHD as a second-line modality following continuous renal replacement therapy techniques after improvement of hemodynamic status [1], or main end point restricted to the first episode of hypotension, are center or study specific. Nevertheless, the strong adherence to practice guidelines aiming to limit hemodynamic instability during IHD sessions [2] ensures that IHD management of study patients reflects general practice, although a selection bias cannot be ruled out.

Second, the lack of significant difference regarding effective fluid removal by IHD between hypotensive episodes related or unrelated to preload dependence could have been related to a reevaluation of planned fluid removal by the physician in charge during IHD, in relation with hemodynamic instability. However, similar results were obtained using planned fluid removal (data not shown).

Third, PLR was performed from the supine position, while one study suggested that starting from the semirecumbent position increases the diagnosis performance of the PLR test [26], since it may mobilize venous blood from the splanchnic compartment in addition to venous blood from the lower limbs. However, this study [26] was restricted to volume-responder patients, and respective sensitivity and specificity of both tests could not be computed. To the contrary, a meta-analysis of 23 studies did not find any effect of the starting position on diagnosis accuracy of the PLR test [27]. However, assuming a conservative assumption of a lower sensitivity of the PLR test performed from the supine position (although not identified by meta-analysis), we cannot rule out that the prevalence of preload dependence was underestimated in the present study.

Four, due to the non-interventional nature of the study, we are unable to conclude regarding the effect of therapeutic interventions after hypotension onset (e.g., of change in fluid removal settings, fluid administration, vasopressor change...), and their effect on the PLR test result.

Five, cardiac index was not assessed by the thermodilution technique during hypotension, but solely by pulse contour analysis, whose reliability may be altered by acute changes in the vasomotor tone. However, it was previously shown in 32 patients [28] that the accuracy of continuous cardiac output assessed by the $\mathrm{PiCCO}^{\circ}$ device remained clinically acceptable within 1 hour of the calibration procedure (percentage error lower than $30 \%)$ despite significant change in the vascular tone (as defined by a greater than $15 \%$ variation in systemic vascular resistance). Therefore, the short delay between $\mathrm{PiCCO}^{\circ}$ calibration and hypotension occurrence (35 [15-95] $\mathrm{min}$ ) in the present study and significant decrease in cardiac index during preload-dependent hypotension as predicted by the Franck-Starling mechanism, favors the reliability of the measurement in most patients.

Six, the relatively low number of preload dependenceassociated hypotension episodes in this study weakens the relevance of associated variables as it prevented multivariate analysis of variables associated with preloaddependent hypotension.

\section{Clinical implications}

The low percentage of preload dependence-related hypotension, should it be confirmed in a wider ICU 
Table $\mathbf{5}$ Characteristics of hypotensive episodes with and without preload dependence

\begin{tabular}{|c|c|c|}
\hline Characteristics & $\begin{array}{l}\text { Hypotension without } \\
\text { preload dependence } \\
(n=48)\end{array}$ & $\begin{array}{l}\text { Hypotension with } \\
\text { preload dependence } \\
(n=11)\end{array}$ \\
\hline Age & 70 [58-78] & 64 [59-69] \\
\hline Male gender & $38(79 \%)$ & $7(64 \%)$ \\
\hline SAPS ॥ & 54 [37-60] & $49[41-55]^{\dagger}$ \\
\hline \multicolumn{3}{|l|}{ Reasons for $\mathrm{PiCCO}^{\circledast}$ monitoring } \\
\hline - Septic shock & $25(52 \%)$ & $8(73 \%)$ \\
\hline - Cardiogenic shock & $8(17 \%)$ & $2(18 \%)$ \\
\hline • Other & $15(31 \%)$ & $1(9 \%)$ \\
\hline Time between ICU admission and IHD session (day) & 18 [10-30] & 9 [6-15] \\
\hline SOFA score at the day of IHD session & 9 [7-11] & $10[9-10]$ \\
\hline Mechanical ventilation at IHD session onset & $13(27 \%)$ & $8(73 \%)^{\dagger}$ \\
\hline Inotrope at IHD session onset & $1(2 \%)$ & $1(9 \%)$ \\
\hline Vasopressor at IHD session onset & $25(52 \%)$ & $7(64 \%)$ \\
\hline Vasopressor dose at IHD session onset $\left(\mu \mathrm{g} \cdot \mathrm{kg}^{-1} \cdot \mathrm{min}^{-1}\right)$ & $0.04[0-0.19]$ & $0.01[0-0.13]$ \\
\hline Heart rate at IHD session onset $\left(\mathrm{min}^{-1}\right)$ & 88 [79-96] & $92[83-108]^{\dagger}$ \\
\hline MAP at IHD session onset (mm Hg) & $70[66-77]$ & $72[72-80]$ \\
\hline CVP at IHD session onset (mm Hg) & $8[5-11]$ & $8[6-10]$ \\
\hline $\mathrm{Cl}$ at IHD session onset $\left(\mathrm{L} \cdot \mathrm{min}^{-1} \cdot \mathrm{m}^{-2}\right)$ & $3.4[2.8-3.9]$ & $3.6[3.2-4.1]$ \\
\hline ISVR at IHD session onset (dyne.s. $\mathrm{cm}^{-5}$ ) & 1497 [1294-1711] & 1440 [1160-1636] \\
\hline EVLWI at IHD session onset (mL.kg ${ }^{-1}$ PBW) & $8.8[6.5-12.7]$ & $10.9[9.0-12.4]$ \\
\hline PVPI at IHD session onset & $1.5[1.3-1.9]$ & $2.0[1.6-2.0]^{\dagger}$ \\
\hline Preload dependence at IHD session onset & $3(6 \%)$ & $1(9 \%)$ \\
\hline Arterial lactates $\left(m m o l . L^{-1}\right)$ & $1.3[1.1-1.6]$ & $1.5[1.4-1.9]$ \\
\hline Elevated lactates above upper laboratory limit (2.2 mmol..-1 $)$ & $8(17 \%)$ & $1(9 \%)$ \\
\hline Duration of IHD sessions (min) & $240[240-250]$ & $228[228-240]$ \\
\hline Total fluid removal during IHD session $(\mathrm{mL})$ & 2580 [1738-3400] & $2250[390-2990]$ \\
\hline Fluid removal during IHD session (mL. $H^{-1}$ ) & $576[411-748]$ & $562[95-748]$ \\
\hline Dialyzer blood flow rate at IHD session onset $\left(\mathrm{L} \cdot \mathrm{min}^{-1}\right)$ & $250[250-271]$ & $250[250-295]$ \\
\hline Dialysate flow at IHD session onset $\left(\mathrm{mL} \cdot \mathrm{min}^{-1}\right)$ & $500[500-700]$ & $700[500-700]$ \\
\hline Dialysate temperature at IHD session onset $\left({ }^{\circ} \mathrm{C}\right)$ & 36 [36-36] & $36[36-36]$ \\
\hline Dialysate sodium concentration at IHD session onset (mmol..-1) & 145 [144-149] & $150[145-150]^{\dagger}$ \\
\hline Time between IHD session onset and hypotension (min) & 30 [14-94] & $60[25-135]$ \\
\hline Cumulative fluid removal at time of hypotension $(\mathrm{mL})$ & 265 [10-825] & $300[70-1195]$ \\
\hline
\end{tabular}

Data are medians [first quartile - third quartile] or number (percentage)

$\mathrm{Cl}$ cardiac index, CVP central venous pressure, EVLWI extravascular lung water, IHD intermittent hemodialysis, ISVR indexed systemic vascular resistance, MAP mean arterial pressure, PBW predicted body weight, PVPI pulmonary vascular permeability index, SAPS II Simplified Acute Physiology Score II, SOFA Sequential Organ Failure Assessment score

${ }^{\dagger} p<0.05$ between groups

setting, suggests that hypotension occurring during IHD sessions should not systematically lead to discontinuation of fluid removal, but prompt hemodynamic evaluation of cardiovascular status. This should be achieved by using a hemodynamic device which can reliably classify patients regarding their preload dependence status (e.g., echocardiography, esophageal Doppler, or other cardiac output monitors with the ability to provide real-time measurement of cardiac output during a PLR maneuver [29]...). Furthermore, the high sensitivity of the PVPI at IHD onset to predict occurrence of preload dependence-related hypotension may help to identify at-risk patients and may prompt downward revision of the total planned fluid removal during the IHD 
Table 6 Diagnostic performance of parameters associated with preload dependence-related hypotension in univariate analysis

\begin{tabular}{|c|c|c|c|c|c|c|c|c|c|c|c|}
\hline Parameter & $\mathrm{AUC}\left[\mathrm{Cl}_{95 \%}\right]$ & $\begin{array}{l}\text { Optimal } \\
\text { cutoff }\end{array}$ & $\mathrm{Se}\left[\mathrm{Cl}_{95 \%]}\right.$ & $\mathrm{Sp}\left[\mathrm{Cl}_{95 \%}\right]$ & FP & $\mathrm{FN}$ & PPV & NPV & PLR & NLR & $\begin{array}{l}\text { Youden } \\
\text { index }\end{array}$ \\
\hline PVPI at IHD onset & $0.68^{\dagger}[0.53-0.83]$ & 1.6 & $0.91[0.59-1.00]$ & $0.53[0.42-0.63]$ & 42 & 1 & 0.19 & 0.98 & 1.93 & 0.17 & 0.44 \\
\hline $\begin{array}{l}\text { Mechanical ventilation at } \\
\text { IHD onset }\end{array}$ & $0.69^{\dagger}[0.54-0.85]$ & NA & $0.64[0.32-0.88]$ & $0.75[0.65-0.83]$ & 24 & 4 & 0.23 & 0.95 & 2.55 & 0.15 & 0.39 \\
\hline HR at IHD onset $\left(\mathrm{min}^{-1}\right)$ & $0.60[0.38-0.81]$ & 105 & $0.36[0.11-0.69]$ & $0.91[0.83-0.96]$ & 9 & 7 & 0.31 & 0.93 & 3.88 & 0.70 & 0.27 \\
\hline $\begin{array}{l}\text { Dialysate sodium concentration } \\
\text { at IHD onset }\left(\mathrm{mmol} \mathrm{L}^{-1}\right)\end{array}$ & $0.63[0.45-0.81]$ & 145 & $0.82[0.48-0.98]$ & $0.45[0.45-0.55]$ & 53 & 2 & 0.15 & 0.96 & 1.48 & 0.41 & 0.27 \\
\hline SAPS ॥ & $0.46[0.30-0.62]$ & 38 & 0.91 [0.59-1.00] & $0.27[0.19-0.37]$ & 53 & 2 & 0.13 & 0.96 & 1.24 & 0.34 & 0.18 \\
\hline
\end{tabular}

AUC area under the curve, $C l_{95 \%} 95 \%$ confidence interval, FP false positive, FN false negative, $H R$ heart rate, NA not applicable, NLR negative likelihood ratio, NPV negative predictive value, PLR positive likelihood ratio, PPV positive predictive value, PVPI pulmonary vascular permeability index, SAPS /I Simplified Acute Physiology Score II, Se sensitivity, Sp specificity

${ }^{\dagger}$ Area under the curve significantly different from 0.5

session, or an increase in IHD session duration. This should obviously be confirmed in future studies, before implementation in the clinical setting.

\section{Conclusions}

In the context of our center, the majority of hypotensive episodes occurring during intermittent hemodialysis are unrelated to preload dependence and should not necessarily lead to reduction of fluid removal by hemodialysis, but should prompt hemodynamic evaluation of cardiovascular status to reliably classify patients regarding their preload dependence status. Lower arterial pressure at dialysis onset, higher SOFA score, and shorter time lag between ICU admission and IHD session are the main risk factors for hypotension during IHD, while high PVPI at dialysis onset and mechanical ventilation are risk factors for preload dependence-related hypotension during IHD and may prompt, if identified at IHD onset, reduction of planned fluid removal during the session, or an increase in session duration.

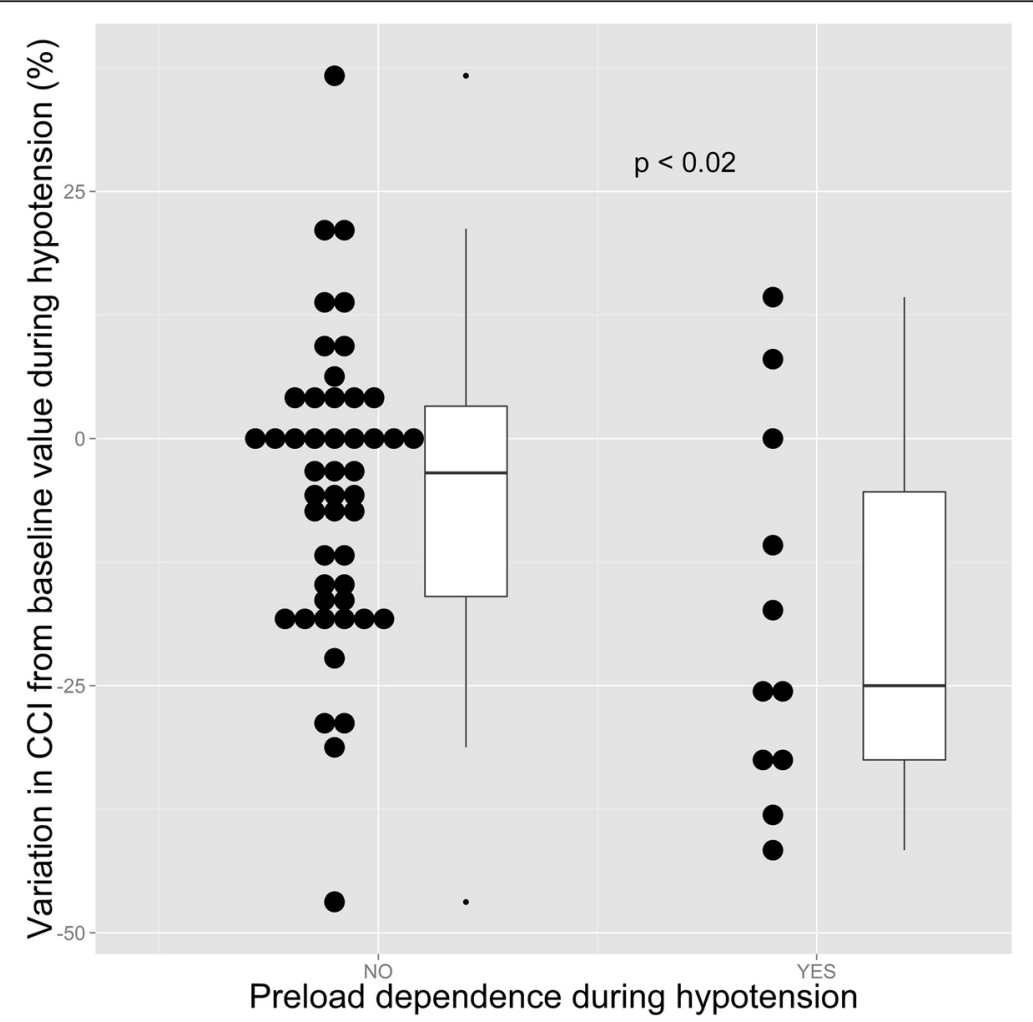

Fig. 2 Variation of CCI from baseline value during hypotension as a function of preload dependence status. Black circles are individual values. CCI continuous cardiac index 


\section{Key messages}

- Lower arterial pressure at dialysis onset, higher SOFA score, and shorter time lag between ICU admission and IHD session are the main risk factors for hypotension during intermittent hemodialysis

- The majority of hypotensive episodes occurring during intermittent hemodialysis are unrelated to preload dependence and should not necessarily lead to reduction of fluid removal by hemodialysis.

- Identified risk factors for preload dependenceassociated hypotension during IHD are high pulmonary vascular permeability index at hemodialysis onset and mechanical ventilation, and may prompt reduction of planned fluid removal during the session, or an increase in session duration.

\section{Additional files}

Additional file 1: Study flow chart. Description of data: study flow chart. (PDF $145 \mathrm{~kb}$ )

Additional file 2: Missing values for each studied variable. Description of data: proportions are computed with either total number of patients $(n=47)$, total number of hypotensive episodes $(n=61)$ or total number of IHD sessions ( $n=107)$, as needed. (PDF $111 \mathrm{~kb}$ )

Additional file 3: Compliance to practice guidelines of intermittent hemodialysis in intensive care units. Description of data: compliance to practice guidelines of intermittent hemodialysis in intensive care units according to reference [2]. Data are number of sessions (percentage of the total number of sessions studied). (PDF $422 \mathrm{~kb}$ )

Additional file 4: Univariate analysis of risk factors associated with at least one hypotensive episode. Description of data: univariate analysis of risk factors associated with at least one hypotensive episode. (PDF $305 \mathrm{~kb}$ )

Additional file 5: Hypotension rates during intermittent hemodialysis in intensive care units in published studies. Description of data: hypotension rates during intermittent hemodialysis in intensive care units in published studies. (PDF $113 \mathrm{~kb}$ )

\section{Abbreviations}

AUC: Area under the curve; Cl $95 \%$ : 95 \% Confidence interval; CVP: Central venous pressure; ICU: Intensive care unit; IHD: Intermittent hemodialysis; MAP: Mean arterial pressure; PLR: Passive leg raising; PVPI: Pulmonary vascular permeability index; ROC: Receiver operating characteristic; SAPS II: Simplified Acute Physiology Score II; SOFA: Sequential Organ Failure Assessment.

\section{Competing interests}

The authors declare that they have no competing interests.

\section{Authors' contributions}

LB made substantial contributions to the study design, analysis, and interpretation of data; drafted the manuscript; approved the version to be published; and agreed to be accountable for all aspects of the work in ensuring that questions related to the accuracy or integrity of any part of the work are appropriately investigated and resolved. FB made substantial contributions to acquisition and interpretation of data; revised the manuscript for important intellectual content; approved the version to be published; and agreed to be accountable for all aspects of the work in ensuring that questions related to the accuracy or integrity of any part of the work are appropriately investigated and resolved. HY made substantial contributions to acquisition and interpretation of data; revised the manuscript for important intellectual content; approved the version to be published; and agreed to be accountable for all aspects of the work in ensuring that questions related to the accuracy or integrity of any part of the work are appropriately investigated and resolved. FG made substantial contributions to acquisition and interpretation of data; revised the manuscript for important intellectual content; approved the version to be published; and agreed to be accountable for all aspects of the work in ensuring that questions related to the accuracy or integrity of any part of the work are appropriately investigated and resolved. VL made substantial contributions to acquisition and interpretation of data; revised the manuscript for important intellectual content; approved the version to be published; and agreed to be accountable for all aspects of the work in ensuring that questions related to the accuracy or integrity of any part of the work are appropriately investigated and resolved. RT made substantial contributions to acquisition and interpretation of data; revised the manuscript for important intellectual content; approved the version to be published; and agreed to be accountable for all aspects of the work in ensuring that questions related to the accuracy or integrity of any part of the work are appropriately investigated and resolved. SD made substantial contributions to acquisition and interpretation of data; revised the manuscript for important intellectual content; approved the version to be published; and agreed to be accountable for all aspects of the work in ensuring that questions related to the accuracy or integrity of any part of the work are appropriately investigated and resolved. ASC made substantial contributions to acquisition and interpretation of data; revised the manuscript for important intellectual content; approved the version to be published; and agreed to be accountable for all aspects of the work in ensuring that questions related to the accuracy or integrity of any part of the work are appropriately investigated and resolved. CG made substantial contributions to the study design, analysis, and interpretation of data; revised the manuscript for important intellectual content; approved the version to be published; and agreed to be accountable for all aspects of the work in ensuring that questions related to the accuracy or integrity of any part of the work are appropriately investigated and resolved. JCR made substantial contributions to the study design, analysis, and interpretation of data; drafted the manuscript; approved the version to be published; and agreed to be accountable for all aspects of the work in ensuring that questions related to the accuracy or integrity of any part of the work are appropriately investigated and resolved.

\section{Acknowledgements}

We wish to thank the following nurses of our ICU whose help was invaluable to conduct the study: P. Couder, X. Forel, T. Garofalo, T. Martinez, A. Saez, V. Urréa, and M. Wilki.

\section{Author details}

${ }^{1}$ Service de Réanimation Médicale, Hôpital De La Croix Rousse, Hospices Civils de Lyon, 103 Grande Rue de la Croix Rousse, 69004 Lyon, France.

${ }^{2}$ Faculté de médecine Lyon-Est, Université de Lyon, Université Lyon I, 92 Rue Pasteur, 69007 Lyon, France. ${ }^{3}$ Institut Mondor de Recherche Biomédicale (IMRB), INSERM 955 Eq13, Faculté de Médecine de Créteil, 8, rue du Général Sarrail, 94010 Créteil, France. ${ }^{4}$ CREATIS, CNRS UMR 5220, INSERM 1044, INSA-Lyon, Université Lyon 1, 7 avenue Jean Capelle, 69621 Villeurbanne, France.

Received: 30 November 2015 Accepted: 11 February 2016

Published online: 23 February 2016

\section{References}

1. Kidney Disease Improving Global Outcomes (KDIGO) Work Group. KDIGO clinical practice guideline for acute kidney injury. Kidney Int Suppl. 2012; 2 $1-138$.

2. Schortgen F, Soubrier N, Delclaux C, Thuong M, Girou E, Brun-Buisson C, et al. Hemodynamic tolerance of intermittent hemodialysis in critically ill patients: usefulness of practice guidelines. Am J Respir Crit Care Med. 2000;162:197-202.

3. du Cheyron D, Terzi N, Seguin A, Valette X, Prevost F, Ramakers M, et al. Use of online blood volume and blood temperature monitoring during haemodialysis in critically ill patients with acute kidney injury: a singlecentre randomized controlled trial. Nephrol Dial Transplant. 2013;28:430-7.

4. Vinsonneau C, Camus C, Combes A, Costa de Beauregard MA, Klouche K, Boulain $T$, et al. Continuous venovenous haemodiafiltration versus intermittent haemodialysis for acute renal failure in patients with multiple-organ dysfunction syndrome: a multicentre randomised trial. Lancet. 2006;368:379-85. 
5. Tonelli M, Astephen P, Andreou P, Beed S, Lundrigan P, Jindal K. Blood volume monitoring in intermittent hemodialysis for acute renal failure. Kidney Int. 2002;62:1075-80.

6. du Cheyron D, Lucidarme O, Terzi N, Charbonneau P. Blood volume- and blood temperature-controlled hemodialysis in critically ill patients: a 6-month, case-matched, open-label study. Blood Purif. 2010;29:245-51.

7. Rosenberg AL, Dechert RE, Park PK, Bartlett RH. Review of a large clinical series: association of cumulative fluid balance on outcome in acute lung injury: a retrospective review of the ARDSnet tidal volume study cohort. J Intensive Care Med. 2009;24:35-46.

8. Sakr Y, Vincent JL, Reinhart K, Groeneveld J, Michalopoulos A, Sprung CL, et al. High tidal volume and positive fluid balance are associated with worse outcome in acute lung injury. Chest. 2005;128:3098-108.

9. Humphrey H, Hall J, Sznajder I, Silverstein M, Wood L. Improved survival in ARDS patients associated with a reduction in pulmonary capillary wedge pressure. Chest. 1990;97:1176-80.

10. Kinet JP, Soyeur D, Balland N, Saint-Remy M, Collignon P, Godon JP. Hemodynamic study of hypotension during hemodialysis. Kidney Int. 1982;21:868-76.

11. Schortgen F. Hypotension during intermittent hemodialysis: new insights into an old problem. Intensive Care Med. 2003;29:1645-9.

12. Daugirdas JT. Dialysis hypotension: a hemodynamic analysis. Kidney Int. 1991;39:233-46

13. Daugirdas JT. Pathophysiology of dialysis hypotension: an update. Am J Kidney Dis. 2001;38 Suppl 4:S11-17.

14. Michard F, Teboul JL. Predicting fluid responsiveness in ICU patients: a critical analysis of the evidence. Chest. 2002;121:2000-8.

15. Pinsky MR. Functional haemodynamic monitoring. Curr Opin Crit Care. 2014;20:288-93

16. Cavallaro F, Sandroni C, Marano C, La Torre G, Mannocci A, De Waure C, et al. Diagnostic accuracy of passive leg raising for prediction of fluid responsiveness in adults: systematic review and meta-analysis of clinical studies. Intensive Care Med. 2010:36:1475-83.

17. Le Gall JR, Lemeshow S, Saulnier F. A new Simplified Acute Physiology Score (SAPS II) based on a European/North American multicenter study. JAMA. 1993;270:2957-63.

18. Vincent JL, Moreno R, Takala J, Willatts S, De Mendonca A, Bruining H, et al. The SOFA (Sepsis-related Organ Failure Assessment) score to describe organ dysfunction/failure. On behalf of the Working Group on Sepsis-Related Problems of the European Society of Intensive Care Medicine. Intensive Care Med. 1996;22:707-10.

19. R Core Team. R: a language and environment for statistical computing. Vienna, Austria: R Foundation for Statistical Computing; 2014.

20. Wiegand H. Survey sampling. Biom Z. 1968;10:88-9.

21. Pinheiro J, Bates D, DebRoy S, Sarkar D, R Core Team. Linear and nonlinear mixed effects models. R package version 3.1-124. 2015. Available at: http://CRAN.R-project.org/package $=$ nlme.

22. Bates D, Maechler M, Bolker B, Walker S. Linear mixed-effects models using Eigen and S4. R package version 1.1-7. 2014. Available at: http://cran.r-project.org/package $=$ Ime4

23. Robin X, Turck N, Hainard A, Tiberti N, Lisacek F, Sanchez J-C, et al. pROC: an open-source package for $\mathrm{R}$ and $\mathrm{S}+$ to analyze and compare ROC curves. BMC Bioinformatics. 2011;12:77.

24. López-Ratón M, Rodriquez-Alvarez MX, Cadarso-Suárez C, Gude-Sampedro F. OptimalCutpoints: an R package for selecting optimal cutpoints in diagnostic tests. J Stat Softw. 2014;61:1-36.

25. Cnaan A, Laird NM, Slasor P. Using the general linear mixed model to analyse unbalanced repeated measures and longitudinal data. Stat Med. 1997; 16:2349-80

26. Jabot J, Teboul JL, Richard C, Monnet X. Passive leg raising for predicting fluid responsiveness: importance of the postural change. Intensive Care Med. 2009;35:85-90.

27. Cherpanath TG, Hirsch A, Geerts BF, Lagrand WK, Leeflang MM, Schultz MJ, Groeneveld AB. Predicting fluid responsiveness by passive leg raising: a systematic review and meta-analysis of 23 clinical trials. Crit Care Med. 2016; doi: 10.1097/CCM.0000000000001556

28. Hamzaoui O, Monnet X, Richard C, Osman D, Chemla D, Teboul JL. Effects of changes in vascular tone on the agreement between pulse contour and transpulmonary thermodilution cardiac output measurements within an up to 6-hour calibration-free period. Crit Care Med. 2008;36:434-40.

29. Guerin L, Monnet $X$, Teboul JL. Monitoring volume and fluid responsiveness: from static to dynamic indicators. Best Pract Res Clin Anaesthesiol. 2013;27:177-85.

\section{Submit your next manuscript to BioMed Central and we will help you at every step:}

- We accept pre-submission inquiries

- Our selector tool helps you to find the most relevant journal

- We provide round the clock customer support

- Convenient online submission

- Thorough peer review

- Inclusion in PubMed and all major indexing services

- Maximum visibility for your research

Submit your manuscript at www.biomedcentral.com/submit
Biomed Central 